Research Article

\title{
Effects of Temperature on Structural Properties of Hydrated Montmorillonite: Experimental Study and Molecular Dynamics Simulation
}

\author{
Wangbing Hong, ${ }^{1}$ Jie Meng, ${ }^{2}$ Changdong Li $\left(D,{ }^{2}\right.$ Shengyi Yan, ${ }^{2} \mathrm{Xin} \mathrm{He}{ }^{2}$ and Guobin $\mathrm{Fu}^{1}$ \\ ${ }^{1}$ Zhejiang Huadong Construction Engineering Co., Ltd., Hangzhou 310000, China \\ ${ }^{2}$ Faculty of Engineering, China University of Geosciences, Wuhan 430074, China
}

Correspondence should be addressed to Changdong Li; lichangdong@cug.edu.cn

Received 24 September 2020; Revised 14 October 2020; Accepted 21 October 2020; Published 7 December 2020

Academic Editor: Chong Xu

Copyright (c) 2020 Wangbing Hong et al. This is an open access article distributed under the Creative Commons Attribution License, which permits unrestricted use, distribution, and reproduction in any medium, provided the original work is properly cited.

\begin{abstract}
Montmorillonite (MMT) is highly sensitive to environmental changes and therefore plays a key role in the structural evolution of rocks and soils and even damage and disasters. The effects of important environmental factors (the temperature and water content) on MMT structural properties require in-depth study. The structure and morphology of sodium montmorillonite (NaMMT) and its thermal products (micro-nanoparticles) were characterized by X-ray diffraction (XRD), Fourier transform infrared (FTIR) spectroscopy, and scanning electron microscopy (SEM). A molecular dynamics (MD) simulation was performed to investigate how temperature (below the failure temperature of the Na-MMT crystal layer) affects the structural properties of hydrated MMT. (1) The laboratory results showed that increasing the temperature significantly affected water molecules, and the particle aggregates exhibited inhomogeneous thermal expansion. The interlayer structure collapsed at $500-700^{\circ} \mathrm{C}$. (2) In the simulation, the pull-off force inhibited interactions among oxides, crystal layers on both sides of the sample, and the bonding structure of water molecules, thus exposing the stress on the bonding body for analysis. The MMTultimate stresses in the $X, Y$, and $Z$ directions all trended downward with increasing water content and temperature. (3) Environmentally induced damage was most likely to occur in the $Z$ direction. Increasing the number of interlayer water molecules increased the layer spacing and considerably weakened van der Waals forces, such that the roles of the electrostatic force and the interlayer hydrogen bond network gradually became significant. The most significant impact of increasing the temperature was reflected in the hydrogen bonding network, resulting in the destruction of the interlayer water bridge, the gradual failure of the layered bonding structure, and the formation or development of cracks. This improved understanding of the structural properties of MMT aggregates under environmental change advances research on the evolutionary behaviour of nano-, micro-, and macrostructures of rocks and soils.
\end{abstract}

\section{Introduction}

Structural changes in rocks and soils under environmental change are often accompanied by damage and even disasters, posing potential hazards to human and property. In recent years, increasing numbers of scholars have been focusing on components of geotechnical systems that are sensitive to environmental changes, because these materials play a determining role in changing the system [1-11]. Macrobehaviour is the cumulative manifestation of microstructural changes. The breakdown of aggregates leads to the expansion of existing cracks, the formation of new microcracks, and the structural collapse of minerals, thereby changing geotechnical properties. Environmental changes frequently trigger and accelerate this process [1-7]. Humidity and temperature are environmental triggers that significantly impact the structure and physicochemical properties of many rocks and soils.

Pores with different scales in rocks and soils provide storage space for water molecules. Changes in humidity may trigger mineral dissolution-crystallization and structural expansion or contraction, leading to pore collapse, the development of existing cracks (pores), or the creation of new 
cracks [5, 12-17], which in turn leads to the structural deterioration or even destabilization of rocks and soils. Fire, friction, and burial depth all change the ambient temperature. Rapid temperature increases affect the mechanical properties of rocks and soils [18, 19]. Frictional sliding in faults during accelerated slip leads to a large increase in temperature which thermally activates physicochemical processes. Friction during landslides can produce temperature increases above $800^{\circ} \mathrm{C}$, which accelerates sliding $[20,21]$.

The stability of the rock and soil structure largely depends on that of the main constituent minerals (or weak minerals) to environmental changes. Over the last few years, many scholars have conducted detailed studies on special rocks and soils, such as loess [4, 22, 23], sliding zone soils $[24,25]$, bentonites [26], and soft rocks [27, 28], demonstrating that carbonates, soluble salts, and clay minerals are extremely sensitive to environmental change. Layered clay minerals are often considered to play a key role in the multiscale evolution of many rock and soil structures by controlling the mechanical properties and solute transport in many natural and engineered environments.

Damage to rocks and soils or even the initial structural alteration of a large landslide may begin with changes in the deformation or deposit pattern of clay minerals. Montmorillonite (MMT) is a predominantly hydrophilic clay mineral that is widely distributed in nature. MMT can absorb water molecules in saturated and unsaturated environments. This phenomenon is known as hydration and involves the electrostatic forces exerted by interlayer ions and hydrogen bonds formed between water molecules and the $\mathrm{OH}$ group on the MMT 010 surface [29]. The expansion and contraction of MMT result in the development of existing cracks (pores) or the creation of new cracks, which may initiate the structural destruction of rocks and soils. The pore water chemical composition affects the hydromechanical behaviour of natural stiff clays, whereas hydration and swelling are considered the most important processes in MMT $[19,30]$.

Numerous scholars have investigated the microstructural changes in sodium montmorillonite (Na-MMT) induced by temperature or humidity by using techniques such as mercury intrusion porosimetry [31], scanning electron microscopy (SEM) [32], and high-precision X-ray computed tomography [33-35]. Thus, some macroscopic destruction mechanisms have been elucidated and possible structural changes have been predicted, providing an in-depth understanding of the destruction process of Na-MMT. However, research on microstructural evolution has been limited to qualitative studies at the micrometre level. In addition, environmentally induced structural changes in MMT remain difficult to characterize because it is difficult to observe hydrated samples in the natural state. A complete molecular understanding of the effect of temperature on the structural properties of hydrated MMT aggregates is essential to determine structural evolutionary processes in geotechnical systems, such as crack initiation and propagation.

The objectives of this study were to use laboratory tests to determine the effect of temperature on MMT properties, to perform large-scale molecular dynamics (MD) pull-off tests on hydrated MMT at different temperatures (the pull-off measurement determines the effect of humidity on the interaction force between two surfaces in air $[36,37])$, and to explore the mechanical properties and failure mechanism of hydrated MMT in detail.

\section{Materials and Methods}

2.1. Na-MMT Clay (Na-MMC). The Na-MMT used in this study had a sample purity $>98 \%$ and a grain size of 16-20 $\mu \mathrm{m}$. The Na-MMT was obtained from the Nanocor company. First, the samples were air-dried at room temperature (approximately $20^{\circ} \mathrm{C}$ ). The approximately 500 -g airdried samples were then thermally treated in a muffle furnace at temperatures of 100, 200, 300, 400, 500, 600, 700, 800, 900 , and $1000^{\circ} \mathrm{C}$. A heating rate of $10^{\circ} \mathrm{C} / \mathrm{min}$ was used to heat the samples to the prescribed temperature level, which was then maintained for $1 \mathrm{~h}$ to ensure even heating of the specimens (Figure 1 shows the test samples diagrams of sodium montmorillonite and its heat-treated products). The heated samples were naturally cooled to room temperature and used for various laboratory tests, such as SEM and Fourier transform infrared (FTIR) spectroscopy.

2.2. Characterization. All the samples were characterized by FTIR spectroscopy using a Nicolet 6700 spectrometer (with a maximum resolution of $0.019 \mathrm{~cm}^{-1}$ ) over the $4000-400 \mathrm{~cm}^{-1}$ range. A FEI Quanta 450 SEM was used to acquire microstructural images of Na-MMT and its thermal products at different magnifications. The phase changes in Na-MMT at various temperatures were analysed using an X-ray diffractometer (X'Pert Pro MPD diffractometer from PANalytical B.V.) with the following parameters: $\mathrm{CuKa}$, a tube current of $40 \mathrm{~mA}$, a tube voltage of $40 \mathrm{KV}$, and a continuous scanning step of $0.02^{\circ}$. An Anton Paar TTK450 was used over a test temperature range of room temperature $-700^{\circ} \mathrm{C}$.

2.3. MD Simulation. Parallel computing was performed in the supercloud using the LAMMPS code. MD simulations were performed at six different temperatures $(300 \mathrm{~K}, 375 \mathrm{~K}$, $475 \mathrm{~K}, 575 \mathrm{~K}, 675 \mathrm{~K}$, and $775 \mathrm{~K}$ below the failure temperature of the Na-MMT crystal layer) to determine the mechanical properties of hydrated MMT under a pull-off test. The water molecules in the clay-water system were described using the SPC/E water model developed by Berendsen et al. [38]. The CLAYFF [39] force field was used to describe the interactions in the clay system. The simulated Na-MMT had a molecular formula of $\mathrm{Na}_{6}\left(\mathrm{Si}_{62} \mathrm{Al}_{2}\right) \quad\left(\mathrm{Al}_{28} \mathrm{Mg}_{4}\right)$ $\mathrm{O}_{160}(\mathrm{OH})_{32} \cdot \mathrm{nH}_{2} \mathrm{O}$ [40] and lattice parameters of $4 a=4 \times 0.523 \mathrm{~nm}, 2 b=2 \times 0.906 \mathrm{~nm}, \alpha=\gamma=90^{\circ}$, and $\beta=99^{\circ}$. The interlayer spacing $c$ was in the $0.96-1.85 \mathrm{~nm}$ range; that is, $c$ was $1.25,1.53$, and 1.85 for increasing water contents $n$ of 32,64 , and $96 \mathrm{~nm}$, corresponding to approximately $9 \%$, $19 \%$, and $28 \%$, respectively. The unit cell was expanded to generate a periodic supercell of size $20 \times 10 \times 6$ in the $a, b$, and $c$ dimensions. Figure 2 shows the dry, 1-, 2-, and 3-layer hydrated MMT supercells $(0 \mathrm{~W}, 1 \mathrm{~W}, 2 \mathrm{~W}$, and $3 \mathrm{~W}$, respectively). The stress-strain relationship was obtained by 


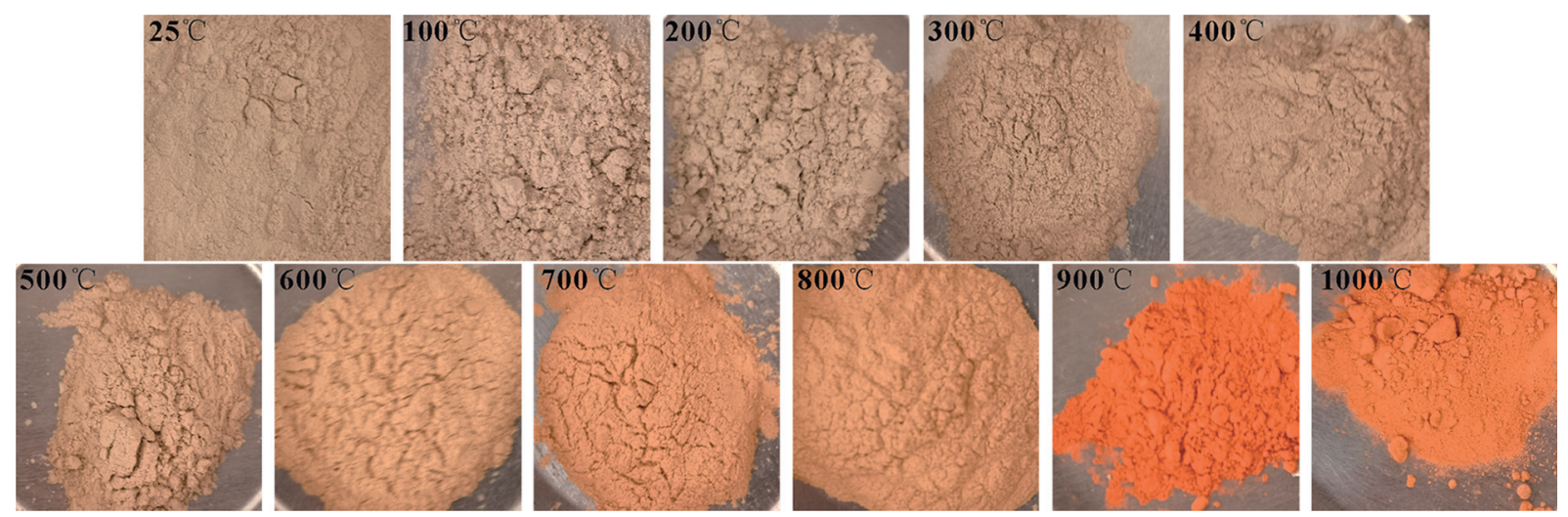

FIGURE 1: Na-montmorillonite and its thermal treatment products.

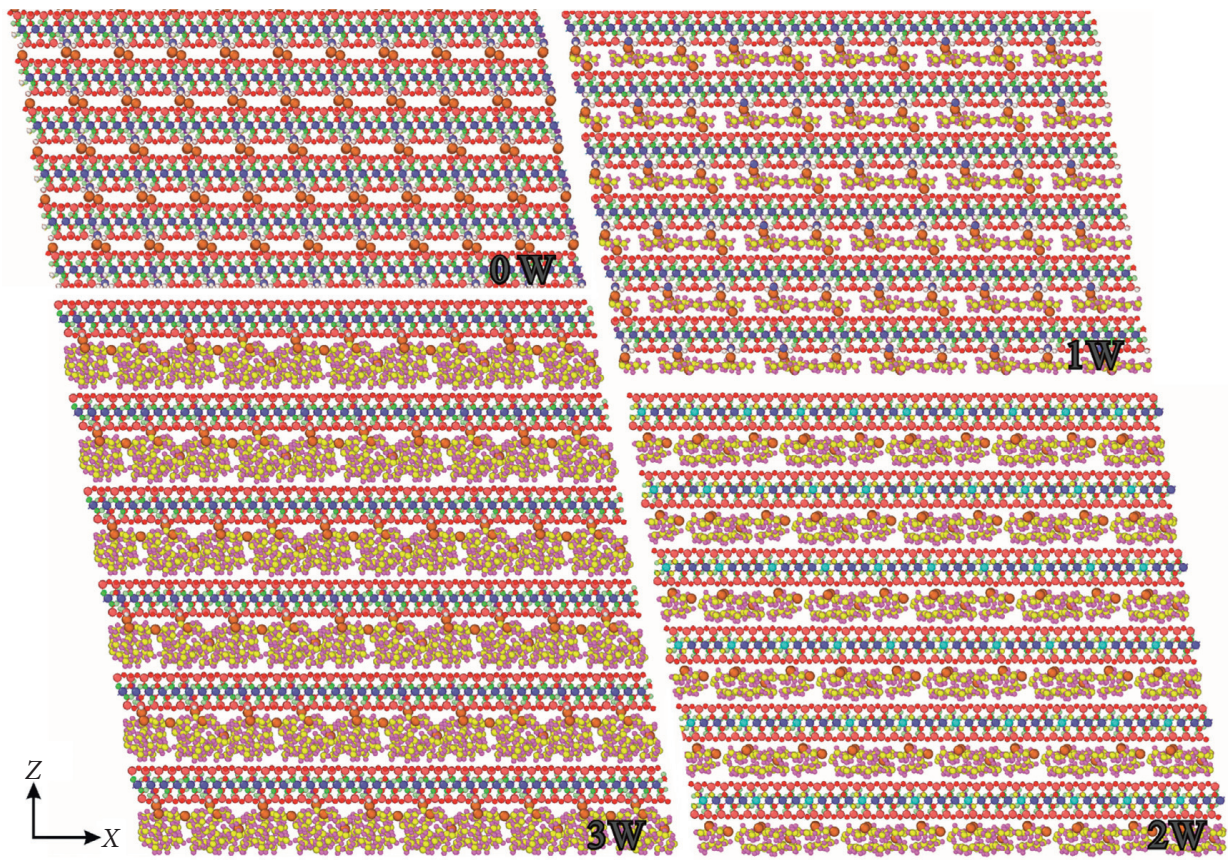

FIGURE 2: MD simulation snapshots showing the four different simulation cells used to study hydrated MMT.

performing an MD simulation in the NPT ensemble (the Nose-Hoover hot bath method was used for temperature control) for uniaxial pull-off loading of the Na-MMT samples, where the pull-off was applied gradually at a constant strain rate $\left(10^{-4} / \mathrm{fs}\right)$. OVITO software was used to visualize the simulation, and the results were deeply analysed in combination with Python program code.

\section{Results}

3.1. FTIR Spectroscopy. The different thermal products were characterized using FTIR spectroscopy. In Figure 3, the $\mathrm{OH}$ contraction vibration peak of crystalline water in Na-MMT appears at $3637 \mathrm{~cm}^{-1}$, the contraction vibration peak of $\mathrm{Al}-\mathrm{Al}-\mathrm{OH}$ and $\mathrm{Al}-\mathrm{Mg}-\mathrm{OH}$ appears at $3452 \mathrm{~cm}^{-1}$, the $\mathrm{OH}$, $\mathrm{Al}-\mathrm{Al}-\mathrm{OH}$, and $\mathrm{Al}-\mathrm{Mg}-\mathrm{OH}$ bending vibration peak of crystalline water appears at $1646 \mathrm{~cm}^{-1}$, the stretch vibration peak of Si-O appears at $1042 \mathrm{~cm}^{-1}$, the bending vibration peak of $\mathrm{Al}-\mathrm{Al}-\mathrm{OH}$ and $\mathrm{Al}-\mathrm{Mg}-\mathrm{OH}$ appears at $917 \mathrm{~cm}^{-1}$, and the $\mathrm{Si}-\mathrm{O}$ bending absorption peak appears at $798 \mathrm{~cm}^{-1}$.

There is no clear redshift in the spectral peaks of the thermal products over $100-600^{\circ} \mathrm{C}$ in Figure 3. However, the various groups exhibited different degrees of redshift when the temperature reached $700^{\circ} \mathrm{C}$.

3.2. X-Ray Diffraction (XRD). Figure 4 shows the XRD spectra of Na-MMT measured under different temperatures. From $25^{\circ} \mathrm{C}$ to $200^{\circ} \mathrm{C}$, the MMT characteristic diffraction peak (001) is sharply enhanced, the diffraction angle $2 \theta$ increases from $6.999^{\circ}$ to $8.82^{\circ}$ (a 26\% increase) [41], and interplanar spacing $d$ (001) shrinks from $1.262 \mathrm{~nm}$ to $1.002 \mathrm{~nm}$ (a $20.6 \%$ decrease). These results show that the number of MMT interlayer water molecules decreases, the interlayer spacing decreases and the interlayers become highly ordered, and the crystal structure becomes more ordered. From 500 to $700^{\circ} \mathrm{C}$, the intensity of the MMT characteristic diffraction peak 


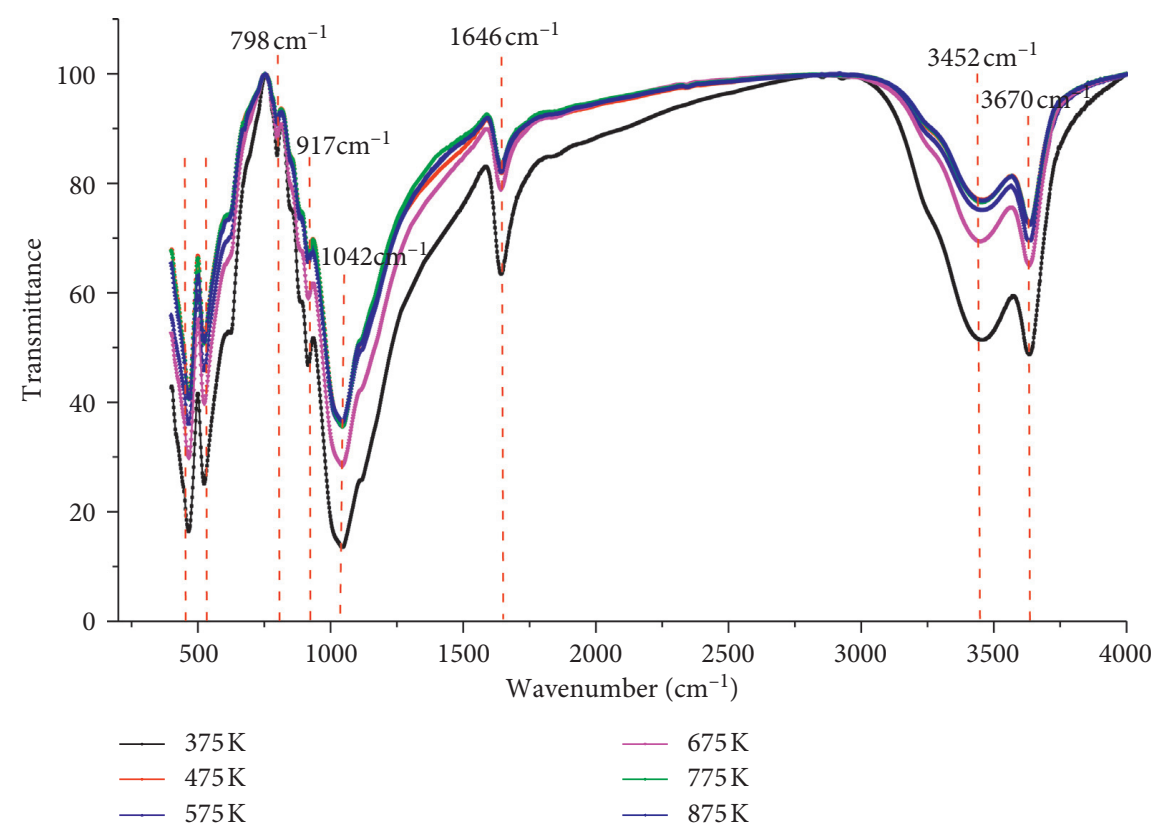

FIGURE 3: IR spectra of MMT and its thermal treatment products.

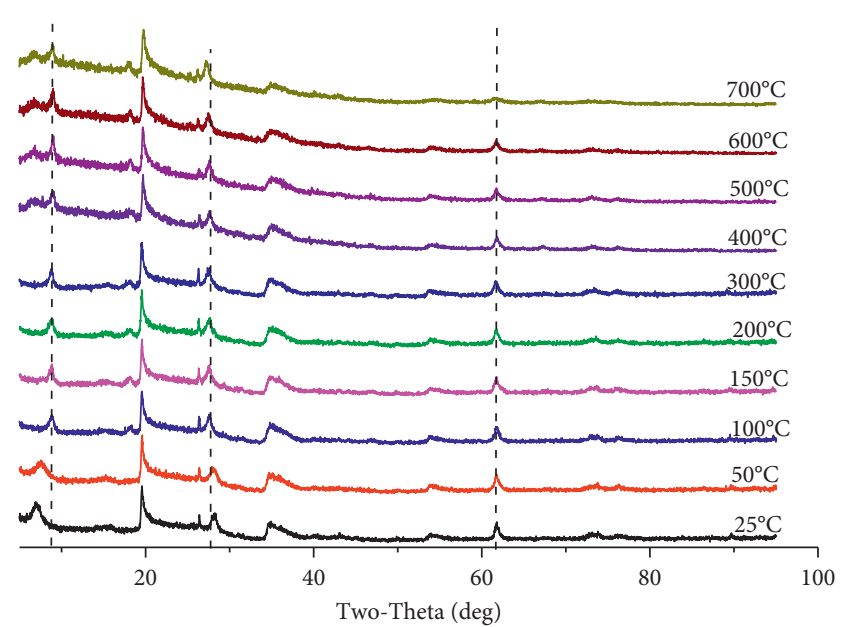

FIGURE 4: XRD patterns for Na-MMT and its thermal products.

(001) remains unchanged, the diffraction angle $2 \theta$ shifts to the left by $0.14^{\circ}$ (a $1.5 \%$ decrease), and the interplanar spacing $d$ (001) increases by $0.015 \mathrm{~nm}$ (a 1.6\% increase). These results show the decomposition of the MMT unstable components (silica-alumina oxide crystals), leading to the collapse of the crystal layer and an increase in the interlayer spacing. The diffraction angle $2 \theta=26.4^{\circ}$ is associated with the small quantity of free silica in the MMT, which does not change significantly with increasing temperature.

3.3. SEM Micrographs. Figure 5 shows the SEM micrographs of the raw and heated samples. Figures $5(\mathrm{a})-5(\mathrm{c})$ correspond to magnification factors of 2000, 6000, and 20,000 , respectively. Significant pore cracking is not observed below $400^{\circ} \mathrm{C}$. The SEM micrographs show intensive crack formation on the Na-MMT surface above $400^{\circ} \mathrm{C}$ and significantly larger particles than at low temperatures. The Na-MMT underwent significant inhomogeneous thermal expansion. The structure was clearly damaged above $700^{\circ} \mathrm{C}$, and clear traces of melting were observed. It can be observed from the test samples that, with the rise of temperature, the colour of montmorillonite also shows a very significant change, which becomes more obvious after the temperature exceeds $700^{\circ} \mathrm{C}$, and approximate orange yellow at $900^{\circ} \mathrm{C}$, and approximate primrose yellow when the temperature reaches $1000^{\circ} \mathrm{C}$. Combined with XRD and FTIR spectroscopy test results, it is found that when the temperature is lower than $700^{\circ} \mathrm{C}$, the temperature has very little influence on the single molecular structure of sodium montmorillonite, while the image of montmorillonite aggregates is very obvious, with obvious thermal expansion phenomenon.

3.4. MD Simulation. Figure 6 shows the uniaxial stressstrain diagrams in the $X, Y$, and $Z$ directions for dry $\mathrm{Na}$ MMT under a pull-off test at $300 \mathrm{~K}$. When the strain in the $X$ and $Y$ directions ranged from 0 to 0.058 and from 0 to 0.065 , respectively, the stress increased linearly with the strain. The slope of the stress-strain curve in the elastic region was used to obtain Young's modulus in the $X$ and $Y$ directions as approximately $193.04 \mathrm{GPa}$ and $199.28 \mathrm{GPa}$, respectively. Table 1 is a comparison between the aforementioned predictions and the corresponding experimental results [37]. All Young's moduli predicted in this study were slightly smaller than simulation results from the literature. The predicted Young's modulus in the $Y$ direction was comparable to the experimental results. Thus, the MD model used in this study can reflect the real mechanical properties of Na-MMT. The maximum stress of approximately 15.17 GPa and $17.15 \mathrm{GPa}$ was obtained at strains of 0.11 and 

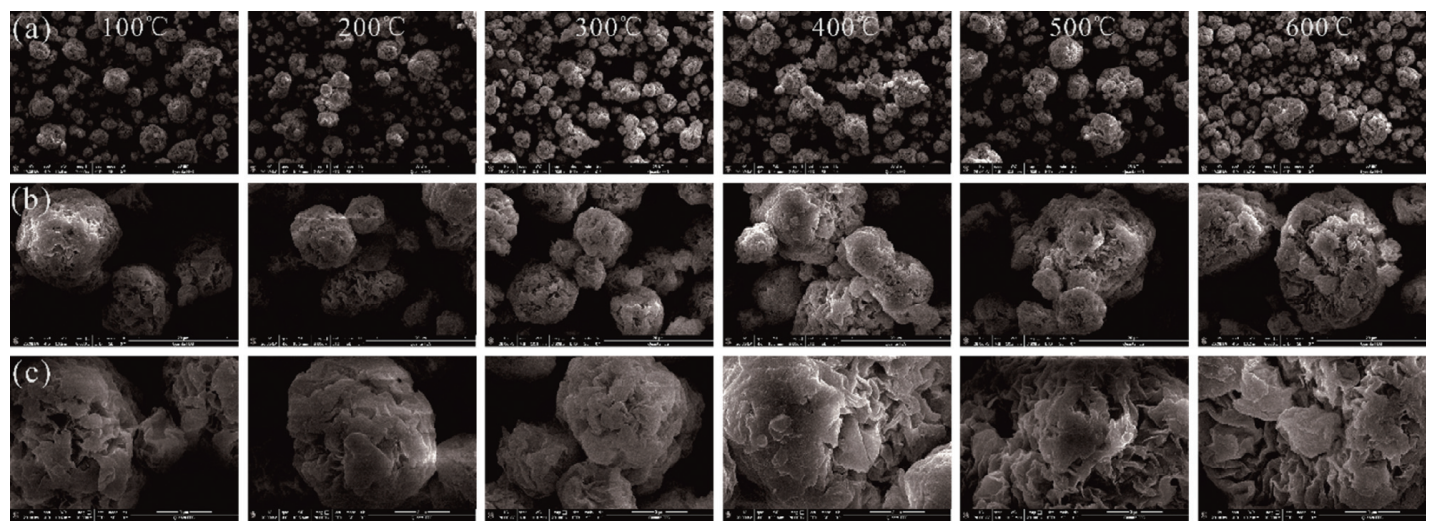

Figure 5: Effect of heating on the specimen microstructure shown at magnifications of (a) 2000, (b) 6000, and (c) $20,000$.

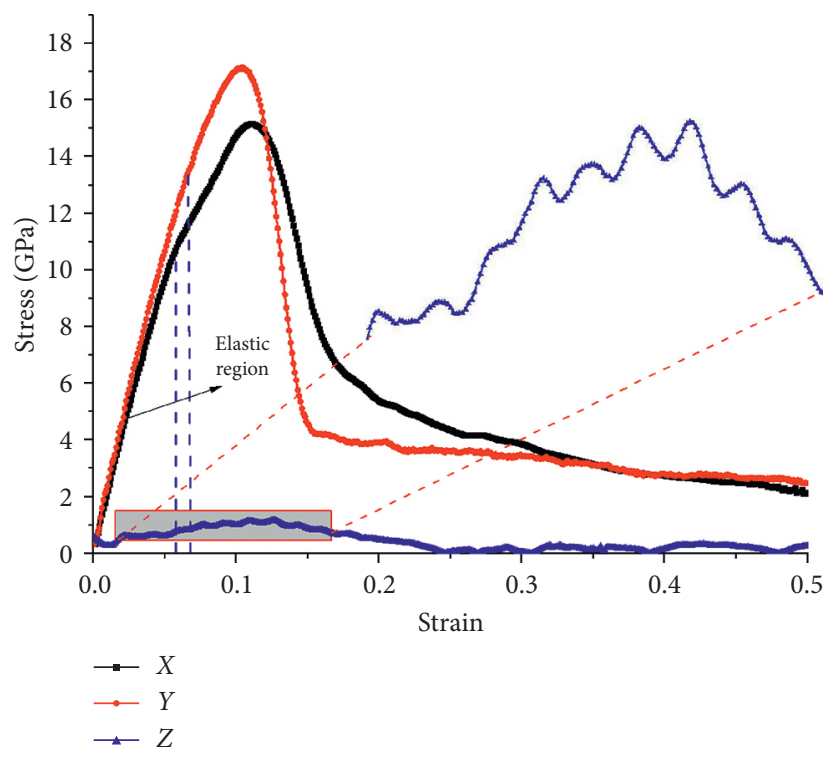

FIgURE 6: Stress-strain curve for Na-MMT at $300 \mathrm{~K}$.

TABle 1: Simulated and experimental Young's modulus for dry Na-MMT.

\begin{tabular}{lccc}
\hline & Young's modulus- $X(\mathrm{GPa})$ & Young's modulus- $Y(\mathrm{GPa})$ & Young's modulus- $Z(\mathrm{GPa})$ \\
\hline MD simulation results from this study & 193.04 & 199.28086 & $\mathrm{ND}$ \\
MD simulation values from the literature & $197-246$ & $249-251$ & $11.5-15$ \\
Experimental results & $5-16$ & $178-265$ & 6.2 \\
\hline
\end{tabular}

ND : not determined.

0.105 in the $X$ and $Y$ directions, respectively. Note that the stress-strain curve in the $Z$ direction exhibits wavy failure with inhomogeneities and multiple peaks, indicating strain failure and separation at low stress in some portions of the Na-MMT sample. The maximum stress of $1.17 \mathrm{GPa}$ was obtained at a strain of 0.126 in the $Z$ direction.

Figure 7 shows how the ultimate stress of hydrated MMT changes during the pull-off test in the $X, Y$, and $Z$ directions. The ultimate stress of Na-MMT samples at the same initial temperature exhibited a clear decreasing trend as the water content increased. The ultimate stress of Na-MMT samples with the same initial water content gradually decreased as the temperature increased, whereas hydrated MMT was more strongly affected by the temperature. The most significant decrease in the ultimate stress of Na-MMT induced by the water content and temperature occurred in the $Z$ direction. The ultimate stress decreased to zero at $775 \mathrm{~K}$ for the 2-layer hydrated $\mathrm{Na}-\mathrm{MMT}$ and at $675 \mathrm{~K}$ for the 3 -layer hydrated Na-MMT. Thus, the MMT structure in the $Z$ direction was damaged in this environment without the influence of external forces.

An in-depth analysis of the failure mode during the pulloff process was performed. The strain correlation function (SCF) is used to describe how chemical bonds in a structure 


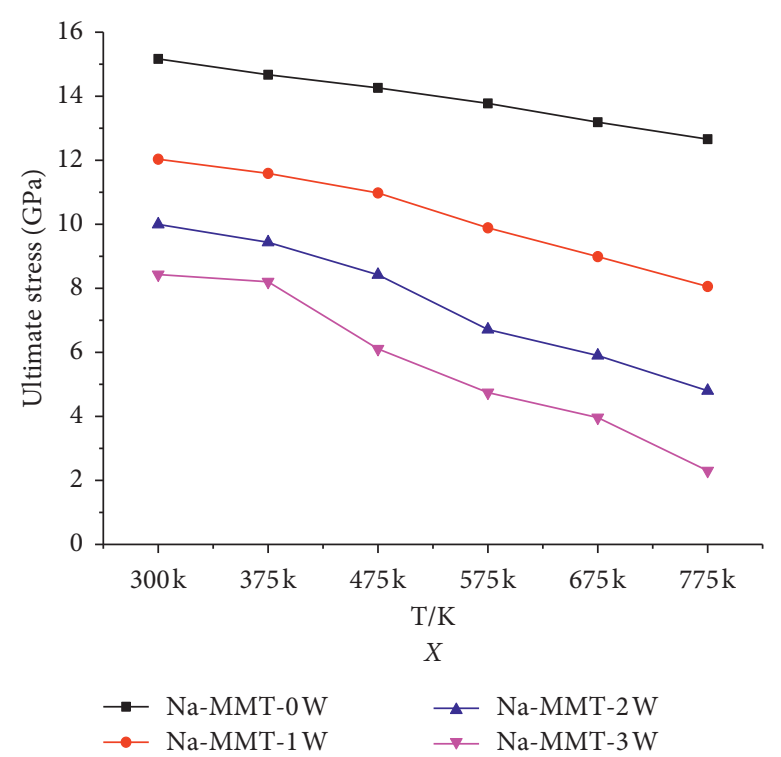

(a)

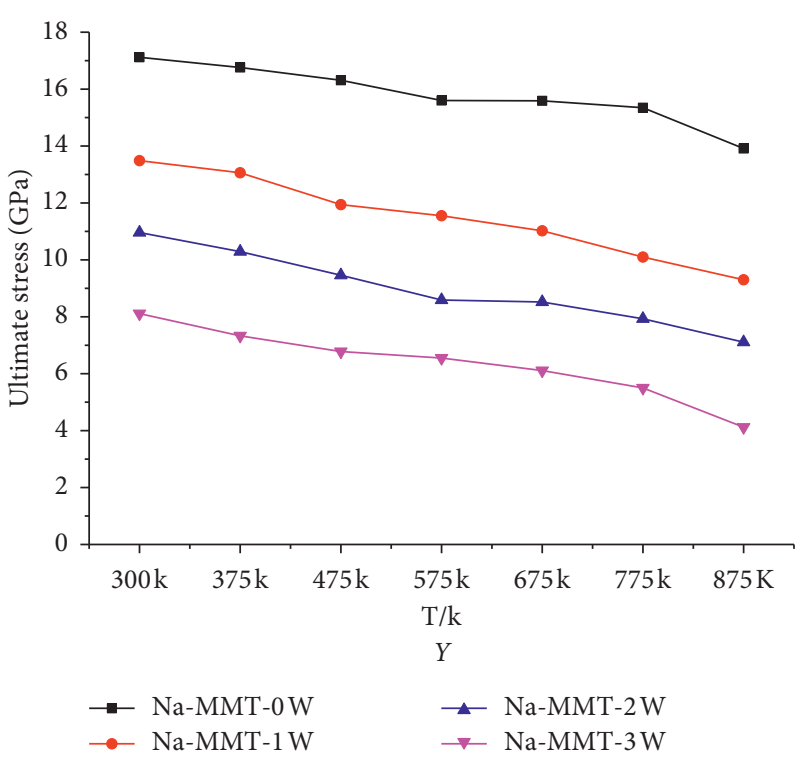

(b)

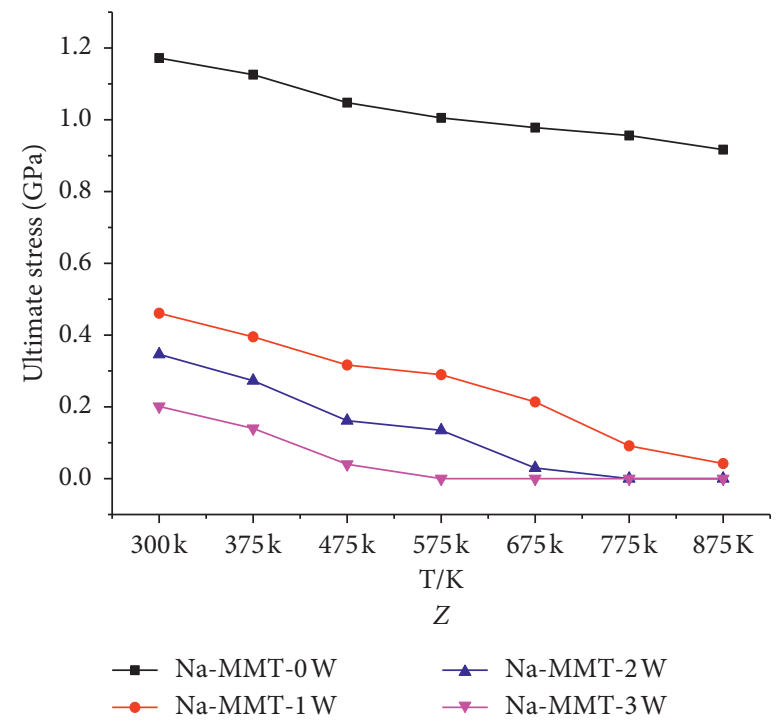

(c)

Figure 7: Ultimate stress in the $X, Y$, and $Z$ directions of hydrated Na-MMT at different temperatures.

change during pull-off. The SCF can be interpreted as a time correlation function (TCF) under strain loading and is shown in [24]:

$$
C(\varepsilon)=\frac{\delta b(\varepsilon) \delta b(0)}{\delta b(0) \delta b(0)}
$$

where $\delta b(\varepsilon)=b(\varepsilon)-b ; b(\varepsilon)$ is a binary operator that is unity if the respective atom pair (e.g., $\mathrm{Al}-\mathrm{O}$ ) is bonded and zero otherwise; and $b$ is the value of $b$ averaged over all simulation time and pairs.

Both aluminium oxide (octahedral and tetrahedral) and tetrahedral silicon oxide were damaged under pull-off in the $X$ and $Y$ directions. Figure 8 shows the uniaxial pull-off failure diagram of 3-layer hydrated Na-MMT along the $X$ direction at $300 \mathrm{~K}$ under a strain of 0.5 . As shown in Figure $8(\mathrm{a}), \mathrm{C}(\varepsilon)$ of all bonds [35] other than the $\mathrm{HO}-\mathrm{OH}$ bond decreased significantly with some fluctuations, implying frequent fracture and formation of new fracture surfaces. As these surfaces formed, $C(\varepsilon)$ stopped decreasing at a well-defined strain. Tetrahedral silicon and octahedral aluminium constitute the main chains in the crystal layer (the tetrahedral aluminium and octahedral magnesium content is relatively low) and largely determine the mechanical properties in the $X$ and $Y$ directions of the layered structure.

Hydrated Na-MMT exhibited a different type of failure under pull-off in the $Z$ direction. The layered structure on both sides of the sample was almost undamaged, and the interlayer ionized water formed a water bridge to prevent failure as the strain increased (Figure 9(a) shows the pull-off failure of the 3-layer hydrated Na-MMT at $300 \mathrm{~K}$ ). Increasing the temperature attenuated the effect of the water 


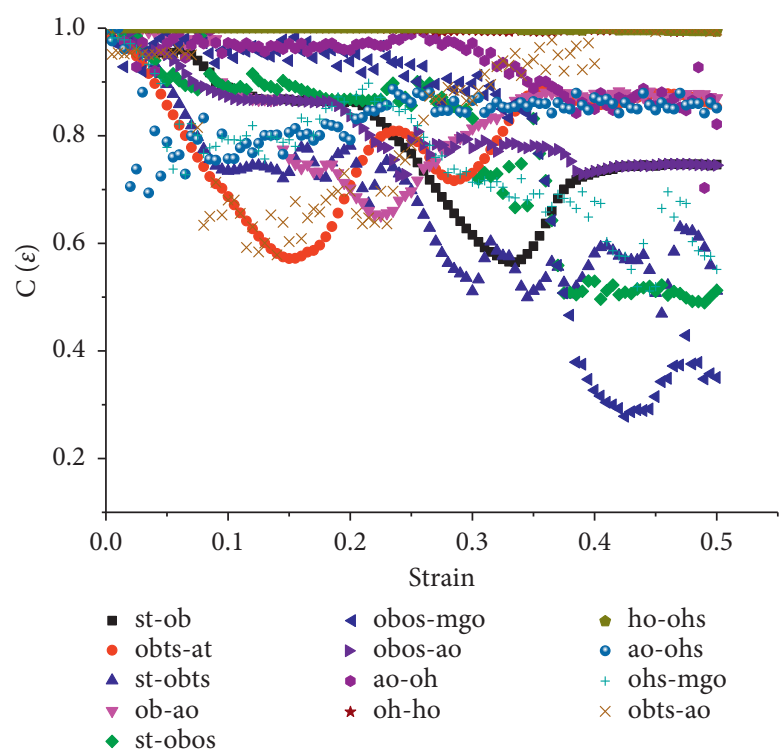

(a)

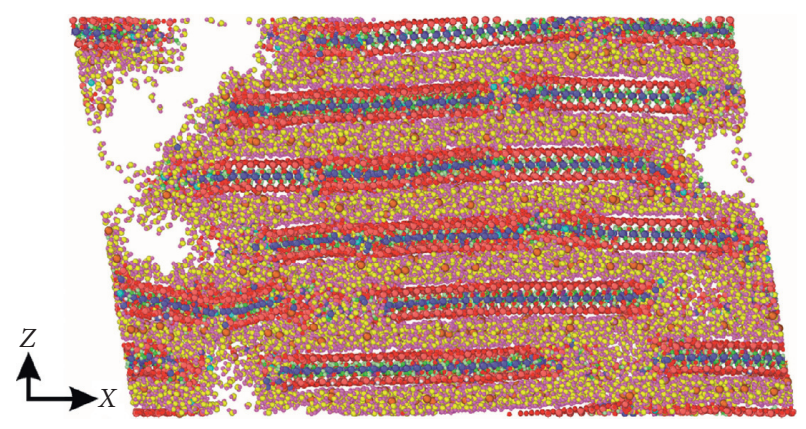

(b)

FIgure 8: Pull-off failure of Na-MMT-3W in the $X$ direction at $300 \mathrm{~K}$. (a) SCF; (b) pull-off failure at strain of 0.5.

bridge (e.g., Figure 9(c) shows the state of the interlayer water molecules in the 3-layer hydrated Na-MMT at $675 \mathrm{~K}$ ).

\section{Discussion}

The aforementioned results confirmed that heating significantly changed the structural properties of hydrated $\mathrm{Na}$ MMT. However, hydrated Na-MMT exhibited different change patterns with increasing temperature. The interlayer water molecules were mainly affected below $400^{\circ} \mathrm{C}$ [42], whereas there was a significant thermal expansion of particles above $400^{\circ} \mathrm{C}$. The $\mathrm{MD}$ pull-off test inhibited the interactions between the oxides and the crystal layers on both sides of the samples, thus exposing the stress on the bonding body for analysis. The results showed that increasing the temperature and the water content produced a clear decreasing trend in the Na-MMT mechanical properties in the $X, Y$, and $Z$ directions with low-stress damage. Clearly, a very strong layered main chain structure was formed by silicon, aluminium, and magnesium oxides and their respective hydroxides in the $X$ and $Y$ directions for hydrated MMT. A pull-off force of several GPa was required for this structure to fail. Failure was more likely to occur along the stacking $(Z)$ direction than in the $X$ and $Y$ directions.

The electrostatic forces in the interlayer bonding system involve counterions, van der Waals interactions, and the hydrogen bonding networks of water molecules $[5,28,37,43]$. In the simulation, the pull-off force suppressed the bonding of crystal layers on both sides of the sample, thus exposing the evolution patterns of the interlayer forces. The increase in the number of water molecules resulted in an increased interlayer spacing, weakened van der Waals forces [44], and the formation of a water bridge by electrostatic interactions between $\mathrm{Na}^{+}$-water molecules and the hydrogen bonding network. An analysis of the radial distribution function (RDF) shows that increasing the temperature scattered more $\mathrm{Na}^{+}$ions on the substrate surface and had a limited effect on the $\mathrm{Na}^{+}$hydration energy $[45,46]$. The threshold for the hydrogen bond distance of interlayer water molecules is usually less than $3 \AA[29,47]$. Increasing the temperature increased the activity of the water molecules, which severely damaged the hydrogen bonding network (Figures 9(b)-9(c)).

MMT aggregates formed by sedimentation, decomposition, and other processes act as a "bridge" between skeletal particles and other minerals in the rocks and soils. These aggregates are not stacked into an ideal structure and exhibit various defects $[30,48]$, such as pores of different scales, which weaken the bonding between MMT aggregates, while providing a wide storage space for water molecules (a "gap" defect [30]). It can be inferred that increasing the humidity and temperature causes the interlayer spacing and activity of water molecules to increase (Figure 9(d)). The presence of defects results in damage to MMT aggregates under low external forces. Therefore, layered clay mineral aggregates with developed cracks are found in different rock and soil microstructures, including the sandstone in Three Gorges Reservoir Region (Figure 9(e)), the Zigui sliding zone soils (Figure 9(f)), and the mudstone of the Xiaoba Formation in southwestern China (Figure 9(g)). These cracks further evolve under environmental changes until the primary structure is completely damaged. Rocks and soils then adapt to the environmental conditions to attain structural stability.

MMT is extremely hydrophilic and sensitive to environmental changes (in unsaturated environments, MMT preferentially adsorbs water molecules over being controlled by the system pore size [49]). Even a very low weak mineral content in rocks and soils may produce changes in the overall structural system [3]. Therefore, MMT-dominated layered clay minerals are often considered to play a key role 

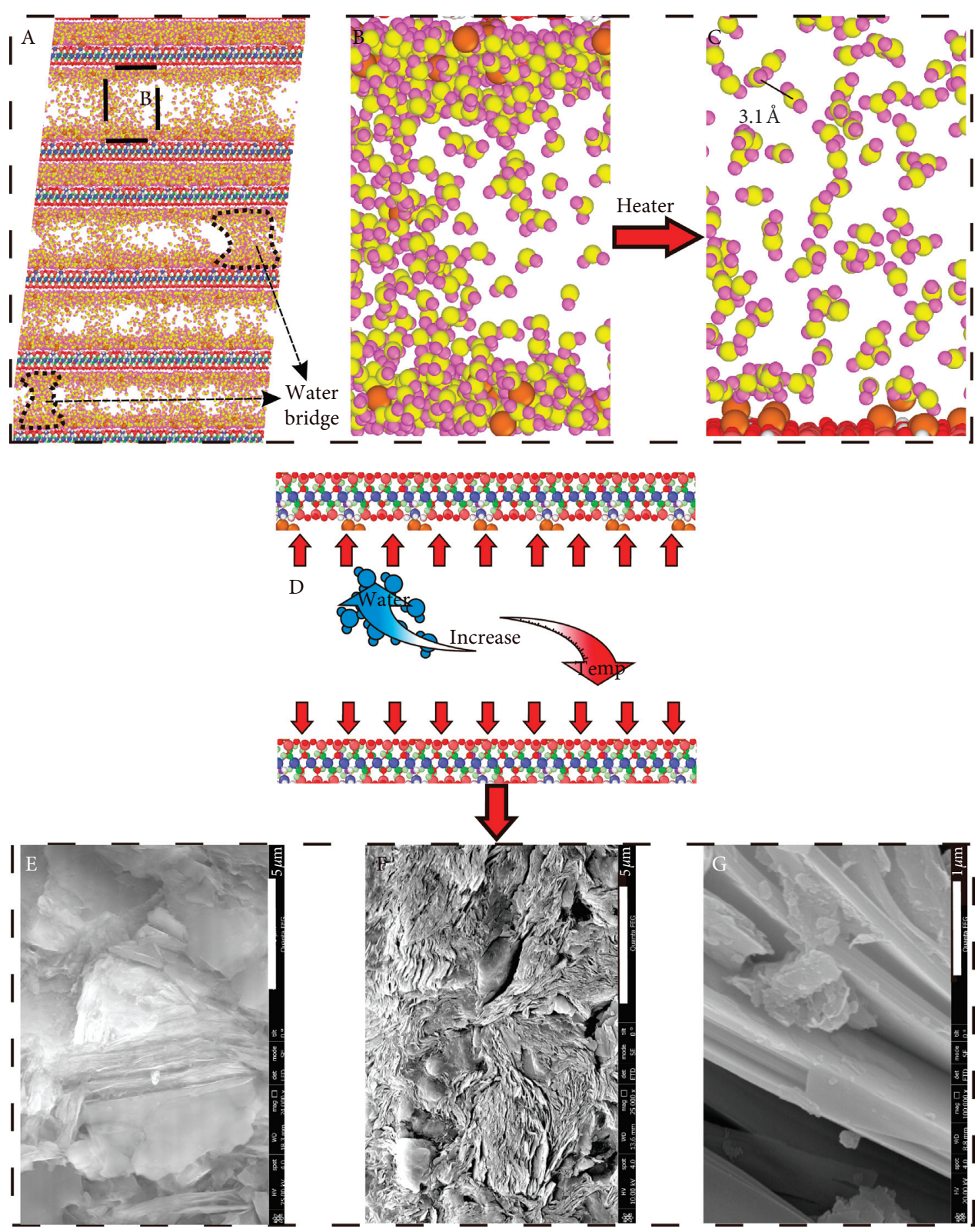

Figure 9: Evolutionary pattern of hydrated MMT.

in the evolution of multiscale structures (i.e., by weakening or destruction of the structure) of many special rocks and soils, such as sliding zone soils, loess, and mudstone. $[3,15,24,25]$.

Many scholars have used MD simulations to extensively study the adsorption-desorption, elasticity, interlayer ions, and other characteristics of hydrated MMT, which have furthered the understanding of the hydration, swelling, and mechanical properties of MMT [50-55]. This study was a continuation of previous research to further explore MMT bonding under temperature and water content changes and the MMT evolution characteristics during destruction processes. The study results provide a deep understanding of the molecular-scale evolution characteristics of rocks and soils that contain MMT and elucidate the evolution mechanism of the structural system. In particular, the results show how structural destruction, or even landslide and fault weakness, is triggered. Thus, a theoretical basis for the protection and risk prevention of rocks and soils is provided.

\section{Conclusion}

Heating significantly changes the structural properties of hydrated Na-MMT. Various change patterns in these properties were observed with increasing temperature. The interlayer water molecules were mainly affected at low temperatures. The thermal expansion of particles became significant above $400^{\circ} \mathrm{C}$. The crystal layers of the Na-MMT began to collapse above $500^{\circ} \mathrm{C}$. An MD simulation was used to determine effect of temperature on the stress-strain curves of different hydrated Na-MMT samples. Pull-off was used to test the bonding of Na-MMT aggregates in different 
directions. The Na-MMT mechanical properties deteriorated to different extents in different directions as the water content and temperature increased.

The failure mode of Na-MMT aggregates in different directions was analysed. Na-MMT was more prone to damage along the stacking direction under environmental changes. During the failure of the layered bonding structure, electrostatic interactions between water molecules and $\mathrm{Na}^{+}$ and the hydrogen bonding network of water molecules resulted in the formation of a water bridge. The most significant impact of the temperature was reflected in the hydrogen bonding network of water molecules. The disappearance of the water bridge weakened bonding in the stacking direction. MMT in nature exhibits various defects and is therefore highly sensitive to environmental changes. Thus, the environmentally induced change mechanism of the MMT structure and the associated complex interactions are accessible and facilitate a complete understanding of the structural evolution process of crack generation and expansion in massive molecular aggregates of hydrated MMT.

\section{Data Availability}

In this paper, the tested montmorillonite was purchased from the high-purity Na-montmorillonite produced by Nanocor, an American company, and all legal organizations can contact Nanocor or contact an agent for purchase (e.g., Beijing Anwu Technology Co., LTD., wishoo@163.com). The software codes used to support the findings of this study were supplied by Jie Meng under license and so cannot be made freely available. Requests for access to these data should be made to Jie Meng (2201910220@cug.edu.cn).

\section{Conflicts of Interest}

The authors declare that there are no conflicts of interest regarding the publication of this paper.

\section{Acknowledgments}

This study was supported by the National Key R\&D Program of China (2018YFC1507200 and 2017YFC1501304), the National Natural Science Foundation of China (Grant nos. 41922055 and 41931295), and the Zhejiang Huadong Construction Engineering Co., Ltd. (KY2019-HDJS-07).

\section{References}

[1] S. Chang, J.-Y. Xu, E.-L. Bai, G.-H. Zheng, and X.-C. Lv, "Static and dynamic mechanical properties and deterioration of bedding sandstone subjected to freeze-thaw cycles: considering bedding structure effect," Scientific Reports, vol. 10, no. 1, Article ID 12790, 2020.

[2] V. K. Kusbach, M. Machek, Z. Roxerová, M. Racek, and P. F. Silva, "Localization effect on AMS fabric revealed by microstructural evidence across small-scale shear zone in marble," Entific Reports, vol. 9, no. 1, 2019.

[3] C. Collettini, A. Niemeijer, C. Viti, and C. Marone, "Fault zone fabric and fault weakness," Nature, vol. 462, no. 7275, pp. 907-910, 2009.
[4] J. Meng and X.-A. Li, "Effects of carbonate on the structure and properties of loess and the corresponding mechanism: an experimental study of the Malan loess, Xi'an area, China," Bulletin of Engineering Geology and the Environment, vol. 78, no. 7, pp. 4965-4976, 2019.

[5] W. M. Yao, C. D. Li, H. B. Zhan, J. Q. Zhou, and X. H. Jiang, "Multiscale study of physical and mechanical properties of sandstone in three Gorges reservoir region subjected to cyclic wetting-drying of yangtze river water," Rock Mechanics \& Rock Engineering, vol. 1, 2020.

[6] S. Stanchi, M. Catoni, M. E. D’Amico, G. Falsone, and E. Bonifacio, "Liquid and plastic limits of clayey, organic C-rich mountain soils: role of organic matter and mineralogy," Catena, vol. 151, pp. 238-246, 2017.

[7] M. Zhang and M. J. Mcsaveney, "Is air pollution causing landslides in China?" Earth and Planetary Science Letters, vol. 481, pp. 284-289, 2018.

[8] C. D. Li, Z. Y. Fu, Y. Wang, H. M. Tang, J. F. Yan, and W. P. Gong, "Susceptibility of reservoir-induced landslides and strategies for increasing the slope stability in the three gorges reservoir area: zigui basin as an example," Engineering Geology, vol. 261, 2019.

[9] W. Yao, C. Li, Q. Zuo, and H. Zhan, "Spatiotemporal deformation characteristics and triggering factors of Baijiabao landslide in Three Gorges Reservoir region, China," Geomorphology, vol. 343, pp. 34-47, 2019.

[10] J. Q. Criss, L. C. Wang, C. D. Li, H. M. Tang, and L. Q. Wang, "Effect of fluid slippage on eddy growth and non-Darcian flow in rock fractures," Journal of Hydrology, vol. 581, p. 124440, 2019.

[11] C. Li, J. Yan, J. Wu, G. Lei, L. Wang, and Y. Zhang, "Determination of the embedded length of stabilizing piles in colluvial landslides with upper hard and lower weak bedrock based on the deformation control principle," Bulletin of Engineering Geology and the Environment, vol. 78, no. 2, pp. 1189-1208, 2017.

[12] W.-b. An, L. Wang, and H. Chen, "Mechanical properties of weathered feldspar sandstone after experiencing dry-wet cycles," Advances in Materials Science and Engineering, vol. 2020, Article ID 6268945, 15 pages, 2020.

[13] F. Zhao and Q. Sun, "Combined effects of cooling rate and salt on physical properties of yellow sandstone collected from Eastern China," Arabian Journal of Geoences, vol. 13, 2020.

[14] M. Julina and T. Thyagaraj, "Combined effects of wet-dry cycles and interacting fluid on desiccation cracks and hydraulic conductivity of compacted clay," Engineering Geology, vol. 267.

[15] W. Y. Ni, F. Wen, Y. Bo, D. L. Sheng, and W. Tingting, "Characterization and evolution of three-dimensional microstructure of Malan loess," Catena, vol. 192, Article ID 104585, 2020.

[16] Y. Li, W. Zhang, S. He, and A. Aydin, "Wetting-driven formation of present-day loess structure," Geoderma, vol. 377, 2020.

[17] J. Wang, T. Gu, M. Zhang, Y. Xu, and J. Kong, "Experimental study of loess disintegration characteristics," Earth Surface Processes and Landforms, vol. 44, pp. 1317-1329, 2019.

[18] F. Zhang, R. Kong, and J. Peng, "Effects of heating on compositional, structural, and physicochemical properties of loss under laboratory conditions," Applied Clay Science, vol. 152, pp. 259-266, 2018.

[19] L. N. Y. Wong, Y. Zhang, and Z. Wu, "Rock strengthening or weakening upon heating in the mild temperature range?" Engineering Geology, vol. 272, Article ID 105619, 2020. 
[20] H. Wei, R. Huang, M. Mcsaveney, X. H. Zhang, and T. Shimamoto, "Mineral changes quantify frictional heating during a large low-friction landslide," Geology, vol. 46, no. 3, 2018.

[21] Sung, "Quasi-equilibrium melting of quartzite upon extreme friction," Nature Geoscience, vol. 10, pp. 436-441, 2017.

[22] P. Li, S. Vanapalli, and T. Li, "Review of collapse triggering mechanism of collapsible soils due to wetting," Journal of Rock Mechanics \& Geotechnical Engineering, vol. 8, no. 2, 2016.

[23] Y. Wang, A. Zhang, W. Ren, and L. Niu, "Study on the soil water characteristic curve and its fitting model of Ili loess with high level of soluble salts," Journal of Hydrology, vol. 578, 2019.

[24] J. Chen, F. Dai, L. Xu et al., "Properties and microstructure of a natural slip zone in loose deposits of red beds, southwestern China," Engineering Geology, vol. 183, pp. 53-64, 2014.

[25] W. Jian, Z. Wang, and K. Yin, "Mechanism of the anlesi landslide in the three Gorges reservoir, China," Engineering Geology, vol. 108, pp. 86-95, 2009.

[26] A. Idiart, M. Laviña, B. Cochepin, and A. Pasteau, "Hydrochemo-mechanical modelling of long-term evolution of bentonite swelling," Applied Clay Science, vol. 195, Article ID 105717, 2020.

[27] S. Zhang, Q. Xu, and Z. Hu, "Effects of rainwater softening on red mudstone of deep-seated landslide, Southwest China," Engineering Geology, vol. 204, pp. 1-13, 2016.

[28] J. W. Zhan, Q. Wang, W. Zhang, Y. L. Shangguan, S. Y. Song, and J. P. Chen, "Soil-engineering properties and failure mechanisms of shallow landslides in soft-rock materials," Catena, vol. 181, Article ID 104093, 2019.

[29] C. Peng, F. Min, L. Liu, and J. Chen, "A periodic DFT study of adsorption of water on sodium-montmorillonite (001) basal and (010) edge surface," Applied Surface Science, vol. 387, no. 30, pp. 308-316, 2016.

[30] M. L. Whittakera, L. R. Comollib, B. Gilberta, and J. F. Banfielda, "Layer size polydispersity in hydrated montmorillonite creates multiscale porosity networks," Applied Clay Ence, vol. 190, p. 2020.

[31] M. V. Villar, R. Gómez-Espina, R. Campos, I. Barrios, and L. Gutiérrez, "Porosity changes due to hydration of compacted bentonite," Unsaturated Soils: Research and Applications, vol. 1, pp. 137-144, 2012.

[32] F. Dellisanti, A. Calafato, G. A. Pini, D. Moro, G. Ulian, and G. Valdrè, "Effects of dehydration and grinding on the mechanical shear behaviour of Ca-rich montmorillonite," Applied Clay Science, vol. 152, pp. 239-248, 2018.

[33] H. Takahashi and Y. Tachi, "3D-microstructure analysis of compacted $\mathrm{Na}$ - and Cs-montmorillonites with nanofocus X-ray computed tomography and correlation with macroscopic transport properties," Applied Clay Science, vol. 168, pp. 211-222, 2019.

[34] S. Saba, P. Delage, N. Lenoir, Y. J. Cui, A. M. Tang, and J.-D. Barnichon, "Further insight into the microstructure of compacted bentonite-sand mixture," Engineering Geology, vol. 168, pp. 141-148, 2014.

[35] A. M. Guerra, "Analysis of the structural changes of a pellet/ powder bentonite mixture upon wetting by X-ray computed microtomography," Applied Clay Ence, vol. 165, pp. 164-169, 2018.

[36] N. V. Zarate, A. J. Harrison, J. D. Litster, and S. P. Beaudoin, "Effect of relative humidity on onset of capillary forces for rough surfaces," Journal of Colloid and Interface Science, vol. 411, pp. 265-272, 2013.

[37] G. E. Valenzuela, "Computer simulation of the effect of wetting conditions on the solvation force and pull-off force of water confined between two flat substrates," The Journal of Physical Chemistry C, vol. 123, no. 2, pp. 1252-1259, 2019.

[38] H. J. C. Berendsen, J. R. Grigera, and T. P. Straatsma, "The missing term in effective pair potentials," The Journal of Physical Chemistry, vol. 91, no. 24, pp. 6269-6271, 1987.

[39] R. T. Cygan, J. J. Liang, and A. G. Kalinichev, "Molecular models of hydroxide, oxyhydroxide, and clay phases and the development of a general force field," The Journal of Physical Chemistry B, vol. 108, no. 4, pp. 1255-1266, 2004.

[40] E. S. Boek, P. V. Coveney, and N. T. Skipper, "Molecular modeling of clay hydration: a study of hysteresis loops in the swelling curves of sodium montmorillonites," Langmuir, vol. 11, no. 12, pp. 4629-4631, 1995.

[41] E. Ferrage, B. Lanson, B. A. Sakharov, N. Geoffroy, E. Jacquot, and V. A. Drits, "Investigation of dioctahedral smectite hydration properties by modeling of X-ray diffraction profiles: influence of layer charge and charge location," American Mineralogist, vol. 92, no. 10, pp. 1731-1743, 2007.

[42] Y. Suo, Z. Chen, and S. S. Rahman, "Changes in shale rock properties and wave velocity anisotropy induced by increasing temperature," Natural Resources Research, pp. 1-11, 2020.

[43] M. Du, P. Liu, J. E. Wong, P. L. Clode, J. Liu, and Y. K. Leong, "Colloidal forces, microstructure and thixotropy of sodium montmorillonite (SWy-2) gels: roles of electrostatic and van der Waals forces," Applied Clay Science, vol. 195, 2020.

[44] L. Liu, L. Moreno, and I. Neretnieks, "A dynamic force balance model for colloidal expansion and its DLVO-based application," Langmuir, vol. 25, no. 2, pp. 679-687, 2009.

[45] M. Camara, J. Xu, X. Wang, J. Zhang, Z. Chen, and X. Li, "Molecular dynamics simulation of hydrated Na-montmorillonite with inorganic salts addition at high temperature and high pressure," Applied Clay Science, vol. 146, pp. 206-215, 2017.

[46] J. O. Titiloye and N. T. Skipper, "Monte Carlo and molecular dynamics simulations of methane in potassium montmorillonite clay hydrates at elevated pressures and temperatures," Journal of Colloid and Interface Science, vol. 282, no. 2, pp. 422-427, 2005.

[47] T. Steiner and G. R. Desiraju, "Distinction between the weak hydrogen bond and the van der Waals interaction," Chemical Communications, vol. 8, no. 8, pp. 891-892, 1998.

[48] I. Siretanu, D. van den Ende, and F. Mugele, "Atomic structure and surface defects at mineral-water interfaces probed by in situ atomic force microscopy," Nanoscale, vol. 8 , no. 15, pp. 8220-8227, 2016.

[49] L. Lahn, P. Bertier, T. Seemann, and H. Stanjek, "Distribution of sorbed water in the pore network of mudstones assessed from physisorption measurements," Microporous and Mesoporous Materials, vol. 295, p. 109902, 2020.

[50] F. Salles, J.-M. Douillard, O. Bildstein et al., "Driving force for the hydration of the swelling clays: case of montmorillonites saturated with alkaline-earth cations," Journal of Colloid and Interface Science, vol. 395, pp. 269-276, 2013.

[51] Y. Zheng and A. Zaoui, "Temperature effects on the diffusion of water and monovalent counterions in the hydrated montmorillonite," Physica A: Statistical Mechanics and Its Applications, vol. 392, no. 23, pp. 5994-6001, 2013.

[52] Y. Zheng and A. Zaoui, "Mechanical behavior in hydrated Namontmorillonite clay," Physica A: Statistical Mechanics and Its Applications, vol. 505, pp. 582-590, 2018.

[53] B. Carrier, M. Vandamme, R. J. M. Pellenq, and H. V. Damme, "Elastic properties of swelling clay particles at finite temperature upon hydration," Transportation Research Part A Policy \& Practice, vol. 70, no. 17, pp. 294-310, 2014. 
[54] M. Holmboe and I. C. Bourg, "Molecular dynamics simulations of water and sodium diffusion in smectite interlayer nanopores as a function of pore size and temperature," Chemical Society Reviews, vol. 42, no. 2, pp. 3628-3646, 2014.

[55] T. Honorio, L. Brochard, and M. Vandamme, "Hydration phase diagram of clay particles from molecular simulations," Langmuir, vol. 33, Article ID 7b03198, pp. 12766-12776, 2018. 